\title{
Anterobasal Temporal Lobe Lesions Alter Recurrent Functional Connectivity within the Ventral Pathway during Naming
}

\author{
Pablo Campo, ${ }^{1}$ Claudia Poch, ${ }^{2}$ Rafael Toledano, ${ }^{3}$ José Manuel Igoa, ${ }^{1}$ Mercedes Belinchón, ${ }^{1}$ Irene García-Morales, ${ }^{3,4}$ \\ and Antonio Gil-Nagel ${ }^{3}$ \\ ${ }^{1}$ Departments of Basic Psychology, and ${ }^{2}$ Biological and Health Psychology, Autonoma University of Madrid, 28049 Madrid, Spain, ${ }^{3}$ Hospital Ruber \\ Internacional, Epilepsy Unit, Neurology Department, 28034 Madrid, Spain, and ${ }^{4}$ University Hospital of San Carlos, Epilepsy Unit, Neurology Department, \\ 28040 Madrid, Spain
}

\begin{abstract}
An increasing amount of evidence supports a crucial role for the anterior temporal lobe (ATL) in semantic processing. Critically, a selective disruption of the functional connectivity between left and right ATLs in patients with chronic aphasic stroke has been illustrated. The aim of the current study was to evaluate the consequences that lesions on the ATL have on the neurocognitive network supporting semantic cognition. Unlike previous work, in this magnetoencephalography study we selected a group of patients with small lesions centered on the left anteroventral temporal lobe before surgery. We then used an effective connectivity method (i.e., dynamic causal modeling) to investigate the consequences that these lesions have on the functional interactions within the network. This approach allowed us to evaluate the directionality of the causal interactions among brain regions and their associated connectivity strengths. Behaviorally, we found that semantic processing was altered when patients were compared with a strictly matched group of controls. Dynamic causal modeling for event related responses revealed that picture naming was associated with a bilateral frontotemporal network, encompassing feedforward and feedback connections. Comparison of specific network parameters between groups revealed that patients displayed selective network adjustments. Specifically, backward connectivity from anterior to posterior temporal lobe was decreased in the ipsilesional hemisphere, whereas it was enhanced in the contralesional hemisphere. These results reinforce the relevance of ATL in semantic memory, as well as its amodal organization, and highlight the role of feedback connections in enabling the integration of the semantic information.
\end{abstract}

\section{Introduction}

Despite the accepted notion that the implementation of cognitive functions by the brain relies on large-scale neural systems, referred to as neurocognitive networks (Meehan and Bressler, 2012), very few studies have used connectivity analyses to investigate the integrated activity among key structures within the semantic memory network (Bar et al., 2006; Heim et al., 2009; Clarke et al., 2011; Wei et al., 2012; Yvert et al., 2012; Bianchi et al., 2013). Some of these studies have shown that interactions between anterior and posterior temporal regions are fundamental for semantic processing (Koubeissi et al., 2012; Hitomi et al.,

Received Feb. 11, 2013; revised June 21, 2013; accepted June 25, 2013.

Author contributions: P.C., C.P., R.T., I.G.-M., and A.G.-N. designed research; P.C., C.P., R.T., I.G.-M., and A.G.-N. performed research; P.C., C.P., R.T., J.M.I., M.B., I.G.-M., and A.G.-N. analyzed data; P.C., C.P., R.T., J.M.I., M.B., I.G.-M., and A.G.-N. wrote the paper.

This work was supported by a research grant from the Spanish Ministry of Science and Innovation (Grant SAF2011-27920) to I.G.-M. P.C. was supported by a Ramón y Cajal Fellowship from the Spanish Ministry of Science and Innovation (RYC-2010-05748). C.P. was supported by Spanish Ministry of Science and Education (AP20094131).

The authors declare no competing financial interests.

Correspondence should be addressed to Dr. Pablo Campo, Departamento de Psicología Básica, Universidad Autónoma de Madrid, Campus de Cantoblanco, 28049 Madrid, Spain. E-mail: pablo.campo@uam.es.

DOI:10.1523/JNEUROSCI.0645-13.2013

Copyright $\odot 2013$ the authors $\quad 0270-6474 / 13 / 3312679-10 \$ 15.00 / 0$
2013). Crucially, a previous work has illustrated a selective disruption of the functional connectivity between left and right anterior temporal lobes (ATLs) in a group of chronic aphasic stroke patients (Warren et al., 2009). Recent research has emphasized the critical contribution of ATL to semantic processing, which has been regarded as an amodal hub essential for coherent semantic representations (Rogers et al., 2004). Most of the neuropsychological evidence supporting this role comes from studies with patients affected by semantic dementia or herpes simplex encephalitis (Noppeney et al., 2007; Mion et al., 2010), two neurological conditions characterized by bilateral degeneration of ATL. Although accumulating evidence has supported a semantic role for the bilateral ATL (Visser and Lambon Ralph, 2011), recent studies have shown that semantic abnormalities, although of milder nature, can be found in unilateral damage conditions, mainly stroke and temporal lobe surgical resection (Antonucci et al., 2008; Lambon Ralph et al., 2012), and also by using repetitive transcranial magnetic stimulation (rTMS; Pobric et al., 2010). Although these studies have demonstrated that unilateral ATL damage can induce semantic impairment, the lesions were extended over large brain areas covering different subregions (Tsapkini et al., 2011), with differential compromise of anteroventral aspects of the temporal lobe (Mikuni et al., 2006; Phan et al., 2007). 
Table 1. Patients' clinical data and brain imaging characteristics

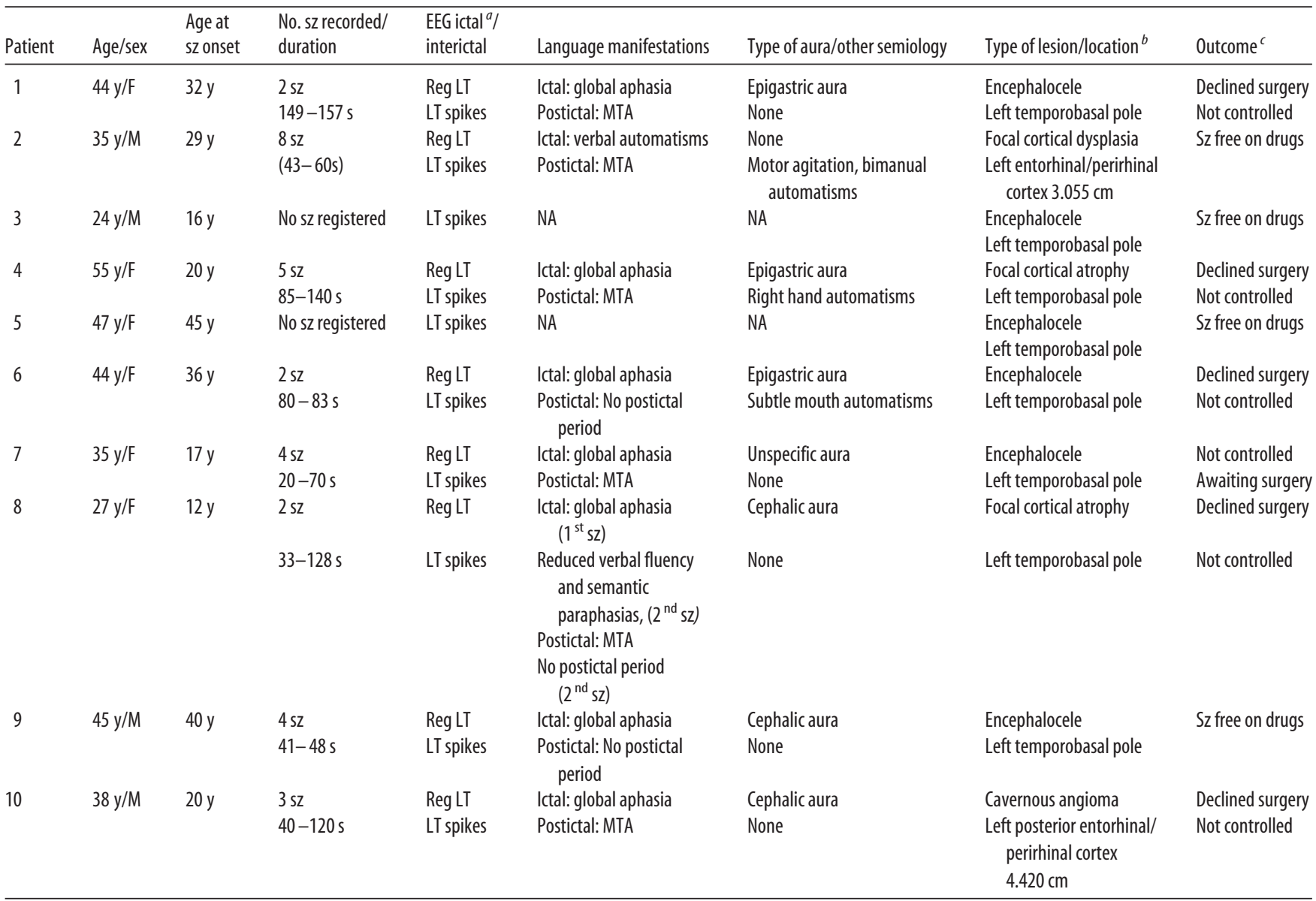

a Ictal EEG in patient with seizures recorded consisted of a regional anterior temporal pattern characterized by rhythmical theta/delta activity that was always evident within the first $20 \mathrm{~s}$ of clinical onset.

${ }^{b}$ Distance from tip of the temporal pole to the anterior border of the lesion.

'Follow-up 2 to 8 years.

y, Years; sz, seizures; LT, left temporal; Reg, regional; MTA, mixed transcortical aphasia; NA, not applicable.

The aim of the current study was to investigate the consequences that small ATL lesions have on the neurocognitive network required for successful semantic processing using an effective connectivity approach. Specifically, we applied dynamic causal modeling (DCM; David et al., 2006) to evaluate the dynamics of neural activity recorded with magnetoencephalography (MEG) while patients with seizures originating from the left anterobasal temporal region and matched controls performed a visual naming task. DCM accounts for directed connections among brain regions and relies on an explicit model of causal influences (Friston et al., 2013). Accordingly, we first determined the neural network that best explained the observed neural response, and then explored whether and how the integrated activity among the brain regions comprising that network was affected by ATL lesions, corresponding to model and system identification analyses. We hypothesized that damage to ATL will lead to an abnormal functioning of the network (Warren et al., 2009; Wright et al., 2012), or a fundamental reconfiguration of it. We also used a battery of semantic tests used in previous studies to further determine the nature and extent of the semantic impairment induced by these lesions (Lambon Ralph et al., 2012).

\section{Materials and Methods}

Subjects

For the purpose of the study all patients with temporal lobe epilepsy (TLE) admitted to our epilepsy unit between January 1998 and June 2012 were reviewed. Patients eligible for this study had aphasic seizures as the main seizure type and a circumscribed epileptogenic lesion located at the temporal pole or the temporal basal region on MRI. Patients with dual pathology (temporobasal lesions and hippocampal sclerosis) and/or lesions extending to other temporal regions were excluded. All imaging protocols included volume acquisition, T1- and T2-weighted, and fluidattenuated inversion recovery (FLAIR) sequences. Video-EEG monitoring of those patients who complied with the inclusion criteria was also reviewed to analyze the type of language impairment during the ictal and postictal period. The type of aphasia was classified according to established criteria (Hillis, 2007). Of the total 169 patients with temporal lobe seizures registered in our epilepsy unit, 10 patients ( 6 females) met our inclusion criteria (Table 1). All patients were right handed. Seizures characterized by some kind of language impairment were the most common seizure type reported by all patients. In addition, nine patients referred infrequent secondary generalized tonic-clinic seizures at the onset of epilepsy. Typical seizures were registered in eight patients (Table 1). Language manifestations during the ictal period consisted of complete speech arrest in seven patients; they remained quiet throughout the ictal period, or just uttered isolated words or short sentences, such as "no," "yes," "wait," or "I feel bad," in response to verbal commands. Two patients also had milder seizures with less expressive impairment. Ictal speech phenomena in just one patient consisted of context repetitive swear words (ictal verbal automatisms). Language comprehension was impaired in all patients as indexed by an inability to follow verbal or written commands during the ictal period. Language deficits continued throughout the postictal period in most patients and were characterized by a gradual recovery of verbal fluency and then comprehension. Ictal 
nonverbal behavior was preserved in seven patients; all of them were alert and turned toward the examiner on verbal request, trying to interact with the examiner and follow his commands. Other ictal features, mainly limited to subtle oral and/or hand automatisms, were found in three patients.

Structural MRI showed discrete lesions that were located in an area expanding from the temporal pole to $4.5 \mathrm{~cm}$ posteriorly, encompassing the left anterobasal temporal cortex in all patients (Table 1; Fig. 1). Lesions were well circumscribed and involved the basal temporopolar cortex, and the entorhinal/perirhinal cortices (Insausti et al., 1998; Frankó et al., 2013). Of note, brain MRI scans were reported as normal initially in eight patients. Lesions in these patients were areas of focal temporopolar cortical atrophy or subtle encephalocele that were recognized only after review of MR images guided by video-EEG findings (i.e., semiology of seizures and EEG patterns) and further imaging with three tesla brain MRI. PET scans were acquired in four patients and showed focal hypometabolism localized to the region of the MRI abnormality in all of them. It is worth noting that the areas affected in our group of patients were previously demonstrated to impair semantic processing in studies using rTMS (Pobric et al., 2007, 2010; Binney et al., 2010) or electrical stimulation (Mikuni et al., 2006). These areas fall well within the region that is resected in standard procedures of epilepsy surgery, after which declines in semantic skills have been reported (Lambon Ralph et al., 2012; for review, see Ives-Deliperi and Butler, 2012). Voxel-symptom lesion mapping studies have demonstrated that the rate of semantic error production arises from damage to anterior regions of the left temporal lobe in a group of patients with aphasia secondary to stroke (Schwartz et al., 2009). This effect has been reproduced using a neuroanatomically constrained computational model (Ueno et al., 2011). Entorhinal and perirhinal cortices has been associated with complex visual representations (Mion et al., 2010). Moreover, the perirhinal cortex has been demonstrated to be necessary for the disambiguation of perceptually and semantically confusable objects (Kivisaari et al., 2012).

A control group consisting of 10 healthy adults strictly matched for age, gender, and education was also recruited for this study. All patients and controls were right-handed. Demographic and clinical information are summarized in Table 2.

\section{Neuropsychological assessment of semantic memory}

We used a group of semantic memory tests that was previously used to assess semantic processing in patients with different aethiologies. Our semantic battery included: (1) a measure of verbal semantic associative knowledge; (2) a measure of visual semantic associative knowledge (Camel and Cactus test); and (3) a category fluency test. The last two tests were extracted from the Cambridge Semantic Battery (Bozeat et al., 2000). Finally, two picture naming tasks were used during MEG recordings (see below). The verbal associative task consists of 30 trials on which the participant is asked to select the word, of four words, that bears a similar meaning to a target word (half of them were abstract, and half concrete). There were a semantic distractor and two unrelated lures. In the visual semantic associative task the participant is asked to select the picture, of four pictures, that is more closely related to a target picture. These two tests were scored for proportion of correct responses. In the category fluency task, the subject is asked to produce as many exemplars as possible in $1 \mathrm{~min}$ from a given category (i.e., birds, breeds of $\mathrm{dog}$, and types of boat).

\section{Stimuli and naming task for magnetoencephalography}

We used a picture-naming task comprising images from the Cambridge 64-item naming task (Bozeat et al., 2000) and the 175-item Philadelphia Naming Test (Roach et al., 1996). Images belonging to both tests were presented only once. Accordingly, a total of 213 images were used. In this task, the participants are confronted with line drawings and are asked to provide their names. The task was adapted for scanning purposes such that in each trial, participants first saw a fixation cross located centrally for $1000 \mathrm{~ms}$, which was followed by a picture lasting in the display 1000 $\mathrm{ms}$. Then, a question mark was shown indicating that participants have to overtly name the presented object as accurately as possible. The next trial began when participants provided an answer or after $5000 \mathrm{~ms}$ elapsed. Picture-naming performance was calculated in terms of the proportion of correct responses. We also analyzed the types of errors. Semantic error production was classified as one of the following subtypes: "pure semantic errors," substituted nouns that related to the target either taxonomically or associatively, and that were not also phonologically related; "non-naming responses," including semantic descriptions, circumlocutions, and/or omissions; and "perceptual errors." Additionally, the number of semantic errors was divided by the number of trials (213) to generate the dependent variable "SemErr" (Schwartz et al., 2009). Following the study of Walker et al. (2011), we also created a variable that added all errors category, "SemTot."

Two factors that were previously shown to influence picture naming in patients with semantic memory impairments (Lambon Ralph et al., 1998; Caramazza and Mahon, 2003; Barense et al., 2010) were also considered in the analyses; namely, frequency (i.e., high vs low) and category domain (i.e., natural vs artificial). Items from both naming tests were classified among the four resulting subsets (i.e., high-frequency natural, high-frequency artificial, low-frequency natural, and low-frequency artificial). To provide an equal number of items in each condition (Jefferies et al., 2009) for the purpose of statistical analyses, 70 high-frequency items (35 natural, 35 artificial) and 70 low-frequency items (35 natural, 35 artificial) were selected from the 213 pool of items. Items were matched for familiarity, frequency (Sanfeliú and Fernández, 1996; Sebastián et al., 2000), and visual complexity (JPEG size was used as a measure of perceptual complexity; Müller et al., 2008) between specific categories (i.e., natural vs artificial), as well as for further subdivisions (i.e., natural high-frequency vs artificial high-frequency; natural lowfrequency vs artificial low-frequency; all $p>0.10$ ). None of the excluded items had generated any errors during task performance.

\section{Magnetoencephalographic data acquisition and analysis}

MEG recordings were obtained using a whole-head 306-channel Vectorview system (Elektra-Neuromag) at a sampling rate of $600 \mathrm{~Hz}$, with a bandpass filter from 0.1 to $200 \mathrm{~Hz}$. Before the recording session, the anatomical landmarks (nasion, and left and right periauricular) and extra points of the head shape, along with the positions of four head position indicator (HPI) coils, were obtained using a 3D digitizer (Fastrak Polhemus). The head position relative to the sensor array was measured at the beginning of the session using four HPI coils. Static bad channels were detected using the MaxFilter program (Elektra-Neuromag), and were interpolated. Artifacts were suppressed by applying a temporally extended signal-space separation method (tSSS; Taulu and Hari, 2009). Data were subsequently analyzed using SPM8 (Wellcome Trust Centre for Neuroimaging, London; http://www.fil.ion.ucl.ac.uk/spm/). Data analyses were conducted using the 204 planar gradiometer channels. The continuous time series for each participant was processed with a Butterworth bandpass filter at $3-30 \mathrm{~Hz}$ and then were epoched off-line to obtain $500 \mathrm{~ms}$ data segments corresponding to $-100-400 \mathrm{~ms}$ peristimulus time. We analyzed epoched data during this period for each trial, and for each participant. Trials including eye blinks or other myogenic or mechanical artifacts were removed using the thresholding criteria implemented in SPM8 (trials containing signal strength exceeding $3000 \mathrm{fT}$ were excluded). Only trials with correct responses were analyzed. Epochs were then baseline corrected from -100 to $0 \mathrm{~ms}$ and then averaged.

Source localization. To define regions of interest for the DCM analysis, multiple sparse priors routine (as implemented in SPM8) was used to estimate the cortical origin of the neuronal response (Friston et al., 2008). For source reconstruction, the multiple sparse priors uses 512 patches of activation which are iteratively reduced until an optimal number and location of active patches are found using a Bayesian greedy search. A tessellated cortical mesh template surface in canonical Montreal Neurological Institute (MNI) anatomical space served as a brain model to estimate the current source distribution (Mattout et al., 2007). Coregistration to the MNI was done using the three anatomical landmarks as well as the extra digitalized points (i.e., headshape). This dipole mesh was used to calculate the forward solution using a digitalized single-shell model. The inverse solution was calculated over a time window from $0-400 \mathrm{~ms}$ after stimulus onset, and averaged over controls and patients (Fig. 2a). Source reconstructions were interpolated into MNI voxel space 


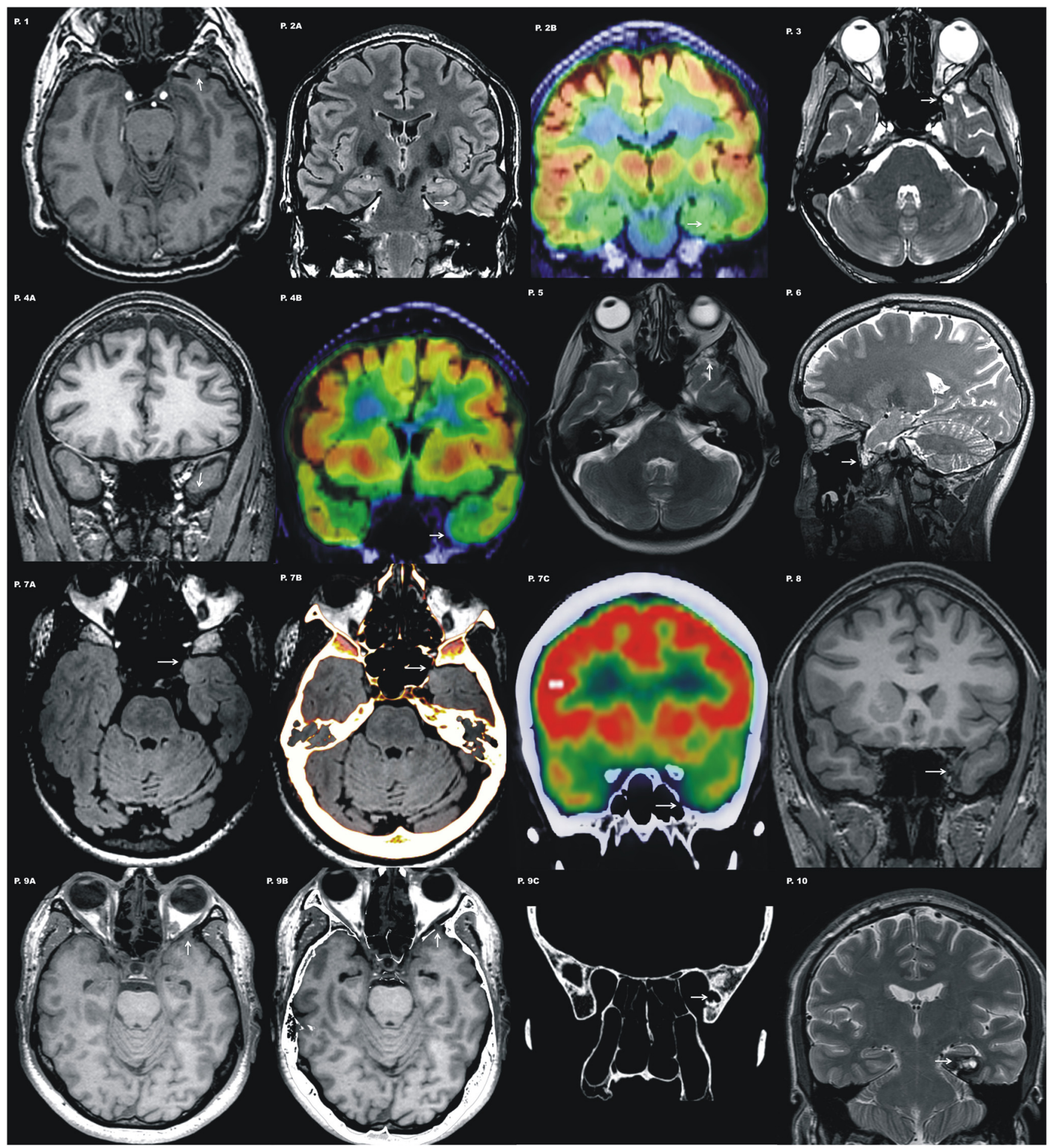

Figure 1. Representative images of different lesion types involving the left temporobasal area for each patient are shown. Note that most of these lesions are subtle and easily missed if not guided by semiology and EEG findings. Patient 1, Axial T1 image shows a small encephalocele at the basal tip of the left temporal lobe. Patient 2, Coronal FLAIR image shows abnormal gyration pattern at the temporobasal surface. Note there is blurring of the gray-white matter encompassing entorhinal and perirhinal cortices (Insausti et al., 1998; Frankó et al., 2013) suggestive of a focal cortical dysplasia (P.2A). PET scan coregistered with MRI shows a circumscribed area of hypometabolism involving these two gyri (P.2B). Patient 3, Axial T2 image shows a small encephalocele that distorts the normal morphology of the temporal pole. Patient 4, Coronal T1 image displays asymmetrical temporal lobes with an unusual morphology of the left temporal pole that appears atrophic (P.4A). PET scan coregistered to MRI shows a subtle area of focal hypometabolism in the same localization (P.4B). Patient5, Axial T2 image acquired along the hippocampal axis shows a small encephalocele that distorts the normal morphology of the temporal pole. Patient 6, Sagittal T2-weighted section displays a pedunculated lesion from the basal tip of the left temporal lobe. The lesion shown corresponds with a small encephalocele that is better identified with a fat saturation sequence. Patient 7, Axial FLAIR section through the temporal tip shows a small area of hyperintensity localized to the inner part of the temporal pole (P.7A). (T scan coregistered with the MRI confirmed a bone defect with the same localization (P.7B). PET scan coregister with the CT scan displays again the minor skull defect together with basal hypomebolism at the tip of the left temporal lobe (P.7C). Patient 8, Coronal $\mathrm{T1}$ image displays asymmetrical temporal lobes with an unusual morphology of the left temporal pole that appears atrophic. Patient 9, Axial T1 parallel to the hippocampus plane demonstrating subtle lobulated appearance of the left temporal pole (P.9A). Fusion of the MRl and CT scans with fine axial cuts identified this abnormality as a small anterobasal temporal encephalocele (P.9B). A bone defect of the inner lamina of the skull at the medial aspect of the middle cranial fossa is evident on CT scan (P.9C). Patient 10, Coronal T2 image shows a cavernous angioma localized at the posterior portion of entorhinal/perirhinal cortex (Insausti et al., 1998; Frankó et al., 2013). 
Table 2. Demographic data and performance on semantic tasks

\begin{tabular}{|c|c|c|c|c|c|c|c|c|c|c|c|c|c|c|c|c|}
\hline \multirow[b]{3}{*}{ Patient No. } & \multirow{2}{*}{\multicolumn{10}{|c|}{ Left hemisphere lesion patients }} & \multicolumn{2}{|c|}{ Patients } & \multicolumn{2}{|c|}{ Controls } & \multirow{4}{*}{$F$} & \multirow{4}{*}{$p$} \\
\hline & & & & & & & & & & & \multirow[t]{3}{*}{ Mean } & \multirow[t]{3}{*}{ SD } & \multirow[t]{3}{*}{ Mean } & \multirow[t]{3}{*}{ SD } & & \\
\hline & 1 & 2 & 3 & 4 & 5 & 6 & 7 & 8 & 9 & 10 & & & & & & \\
\hline Demographic data & & & & & & & & & & & & & & & & \\
\hline Age & 44 & 35 & 24 & 55 & 47 & 44 & 35 & 27 & 45 & 38 & 39.40 & 9.47 & 37.30 & 7.86 & 0.29 & n.s. \\
\hline Level of education, years & 12 & 17 & 17 & 14 & 17 & 17 & 17 & 17 & 17 & 13 & 15.80 & 1.98 & 16.00 & 2.11 & 0.09 & n.s. \\
\hline Semantic tasks & & & & & & & & & & & & & & & & \\
\hline Naming task ${ }^{a, c}$ & 93.06 & 90.71 & 96.79 & 92.71 & 97.05 & 96.53 & 95.75 & 80.64 & 98.18 & 95.14 & 93.65 & 5.12 & 96.25 & 2.21 & 2.17 & n.s. \\
\hline Verbal associative task $^{a}$ & 80 & 93.33 & 93.33 & 90 & 96.67 & 80 & 90 & 80 & 90 & 80 & 87.33 & 6.63 & 88.33 & 5.72 & 0.13 & n.s. \\
\hline Camel \& Cactus ${ }^{a, b}$ & 87.50 & 93.75 & 92.19 & 93.75 & 85.94 & 75 & 89.06 & 89.06 & 87.50 & 82.81 & 87.65 & 5.63 & 92.81 & 3.47 & 6.08 & $<0.05$ \\
\hline Fluency $^{b}$ & & & & & & & & & & & & & & & & \\
\hline Birds & 11 & 7 & 21 & 11 & 9 & 6 & 8 & 6 & 16 & 12 & 10.70 & 4.76 & 16.00 & 4.08 & 7.14 & $<0.05$ \\
\hline Breeds of dog & 9 & 4 & 20 & 7 & 8 & 4 & 6 & 6 & 10 & 7 & 8.10 & 4.60 & 13.00 & 5.21 & 4.97 & $<0.05$ \\
\hline Types of boat & 12 & 6 & 24 & 7 & 10 & 4 & 15 & 10 & 23 & 11 & 12.20 & 6.73 & 10.70 & 2.40 & 0.44 & n.s. \\
\hline
\end{tabular}

Semantic tests results are shown for a selected group of patients individually $(n=10)$ and for a group of control healthy subjects $(n=10)$. n.s., Not significant.

a Percentage of correct answers.

${ }^{b}$ Tests extracted from the Cambridge Semantic Battery.

'Stimuli shared by Cambridge naming test and Philadelphia naming test were presented only once.

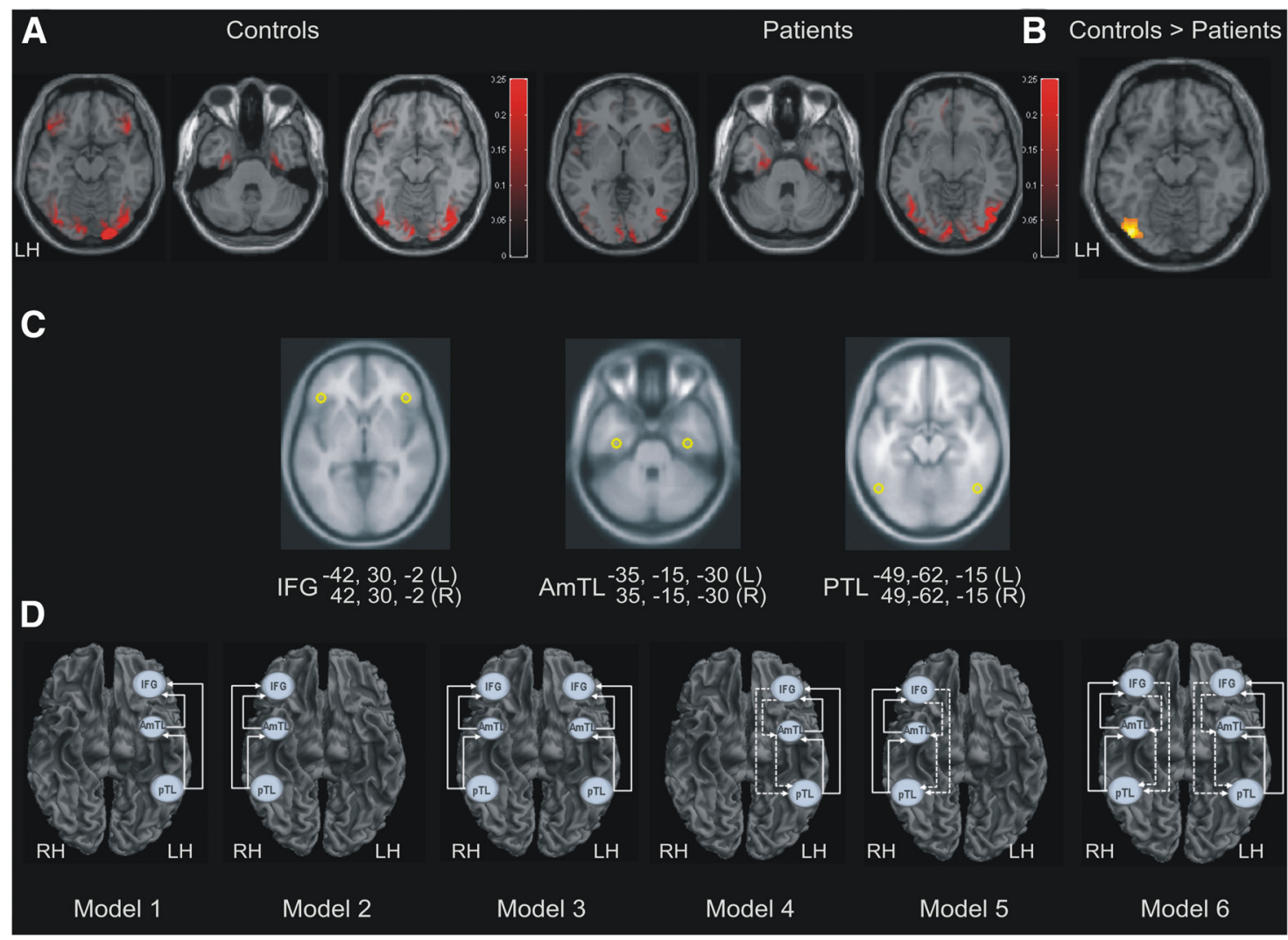

Figure 2. A, Axial views of the source localization for the grand-mean responses averaged over controls (left) and over patients (right) projected into MNI voxel space and superimposed on the template structural MRI image. $\boldsymbol{B}$, Posterior temporo-occipital region showing significantly increased activity in controls relative to patients. $\boldsymbol{C}$, Sources of activity, modeled as dipoles (estimated posterior moments and locations) superimposed on an MRI of a standard brain in MNI space, and their coordinates. D, Outline of the six DCM models for the effective connectivity analysis shown on axial brain schematics. Models differed in hierarchical levels (i.e., sources and extrinsic connections). Model sources could be unilateral (left or right), or bilateral. Arrows between the regions indicate the directionality of the connections feedforward or backward (dashed lines). IFG, Inferior frontal gyrus; AmTL, anteromedial temporal lobe; PTL, posterior temporal lobe; LH, left hemisphere; RH, right hemisphere.

and analyzed using statistical parametric mapping (Kilner and Friston, 2010), in the usual way (Moran et al., 2013). A contrast of evoked signal strength was conducted using a two-sample $t$ test. Differences between groups were thresholded at $p<0.005$ (uncorrected).

Effective connectivity analysis: dynamic causal modeling. DCM is a hypothesis-driven method that relies on the specification of a plausible biophysical and physiological model of interacting brain regions (Stephan and Friston, 2007). DCM for evoked related fields allows for inferences about the neural networks or architectures that generate elec- tromagnetic responses. These architectures are parameterized in terms of coupling within and between neuronal sources. Generally, Bayesian model comparison is used to compare different models or to find the model with best evidence (Penny et al., 2004). In our analyses, we first optimized the model and then compared the parameter estimates, under the best model, to test for group differences in effective connectivity. The sources or nodes of the network architecture were specified on the basis of the inverse solutions (i.e., multiple sparse priors; Friston et al., 2008), and were therefore optimized for the particular subjects studied (Fig. 2a). 
Sources were then modeled as equivalent current dipoles positioned symmetrically in each hemisphere, in a canonical brain (MNI) space, with prior mean location coordinates $(x, y, z)$ at: posterior temporal lobe (PTL): $-49,-62,-15$ (left); 49, -62, -15 (right); anteromedial TL (AmTL): $-35,-15,-30$ (left); 35, $-15,-30$ (right); and IFC: $-42,30$, -2 (left); 42, 30, -2 (right; Fig. 2c). Activation of these regions has been specifically associated with semantic processing of pictures in previous studies (Tyler et al., 2004; Binney et al., 2010; Visser and Lambon Ralph, 2011; Clarke et al., 2013), and are considered part of a ventral network involved in visual object processing (Gilbert and Li, 2013; Kravitz et al., 2013). In all models left and right PTL were chosen as visual input nodes for semantic processing of pictures (Heim et al., 2009). Six models were specified and inverted separately for each subject, using responses from stimulus onset to $400 \mathrm{~ms}$ poststimulus time (Clarke et al., 2013). Model architectures were constructed considering specifications from previous studies (Chan et al., 2011; Clarke et al., 2011; Yvert et al., 2012), and differed in terms of their laterality, and the type of directed connections (see Fig. 2d). Forward and backward connections are defined according to the connectivity rules outlined in Felleman and Van Essen (1991), and specified in DCM to convey feedforward and feedback effects, respectively. To select the most likely model we used a Bayesian model selection procedure (Penny et al., 2004). Statistical inference on models was conducted using a random-effect approach (RFX; Yvert et al., 2012), a method that is preferred when studying heterogeneous populations or when optimal models can vary across participants (Seghier et al., 2010). Model comparison was conducted on controls, patients, and across participants. After selecting the optimal model, its subject-specific parameters were compared with test for group differences (restricting the comparisons to parameter estimates that differed from their prior mean with a posterior confidence of $90 \%$ ). Families of models were also compared to test the laterality of the network (i.e., left vs right vs bilateral; Penny et al., 2010).

\section{Results}

\section{Behavioral results}

Group differences in performance accuracy were analyzed by a multivariate ANOVA (MANOVA) with performance in the semantic tasks as dependent measures and Group (patients and controls) as a factor. Effects were considered statistically significant when $p<0.05$, after Bonferroni correction. Patients were less accurate $(\mathrm{M}=87.66, \mathrm{SD}=5.63)$ than controls $(\mathrm{M}=92.81$, $\mathrm{SD}=3.47$ ) in visual semantic associative knowledge (Camel and Cactus test; $\left.F_{(1,18)}=6.08, p=0.024\right)$. Patients generated less exemplars for the category "birds" $(\mathrm{M}=10.70, \mathrm{SD}=4.76)$ and "breeds of dogs" $(M=8.1, S D=4.1)$ than controls $(M=16.00$, $\mathrm{SD}=4.08 ; \mathrm{M}=13.00, \mathrm{SD}=5.21$, respectively; $F_{(1,18)}=7.14, p=$ $0.016 ; F_{(1,18)}=4.97, p=0.039$, respectively). We failed to detect significant differences between groups in verbal semantic associative knowledge $(p=0.72)$. Regarding the naming task, patients $(\mathrm{M}=93.65, \mathrm{SD}=5.12)$ did not differ from controls $(\mathrm{M}=96.25, \mathrm{SD}=2.21)$ in proportion of correct responses $\left(F_{(1,18)}=2.17, p=0.16\right)$. However, when we considered the types of errors, we observed that patients $(\mathrm{M}=4.90, \mathrm{SD}=4.30)$ made more non-naming errors than controls $(\mathrm{M}=0.90, \mathrm{SD}=1.10$; $\left.F_{(1,18)}=8.10, p=0.011\right)$. Finally, main effects of frequency $\left(F_{(1,17)}=46.74, p<0.001\right)$ and category $\left(F_{(1,17)}=6.30, p=\right.$ 0.022 ) were found, with more errors made for low frequent items and for artificial items. Planned comparisons revealed that patients showed a trend to make more errors for less frequent items $(\mathrm{M}=87.22, \mathrm{SD}=8.71)$ and for artificial items $(\mathrm{M}=88.67, \mathrm{SD}=$ $9.83)$ than controls $(\mathrm{M}=92.90, \mathrm{SD}=4.25 ; \mathrm{M}=95.20, \mathrm{SD}=$ 3.62 ; respectively; $t_{(17)}=1.84, p=0.084 ; t_{(17)}=1.96, p=0.066$; respectively). It was also observed that patients were more prone to make semantic errors when naming low-frequency/artificial objects $(\mathrm{M}=84.33, \mathrm{SD}=11.25)$ than controls $(\mathrm{M}=93.33, \mathrm{SD}=$ $\left.5.65 ; t_{(17)}=2.24, p=0.039\right)$. Only nine patients with available values were included in frequency/category analyses. Table 2 shows the results of the semantic tests for the group of patients individually and for the group of controls.

\section{Source space analysis}

We observed that controls and patients consistently activated several regions in the ventral stream. However, patients exhibited a reduced activity $\left(t_{(18)}=2.96, p<0.005\right)$ in the left posterior inferior temporo-occipital cortex between 200 and $300 \mathrm{~ms}$ after stimulus onset (Fig. 2b).

\section{Bayesian model selection}

Bayesian model selection (RFX) revealed that the most plausible model was Model 6 for controls (model exceedance probability of 0.754 ), patients (model exceedance probability of 0.834 ), and across participants (model exceedance probability of 0.931 ), which included bilateral sources with backward connections (see Fig. 3). Comparison of model families clearly indicated that bilateral models were more likely (exceedance probability of 0.987 ).

\section{Between-subject differences in connectivity}

Once the best model had been determined, group differences in effective connectivity strength were analyzed by a multivariate ANOVA (MANOVA) with connectivity parameters as dependent measures and Group (patients and controls) as a factor. Effects were considered statistically significant when $p<0.05$, after Bonferroni correction. Analyses revealed that the extrinsic backward connection from left AmTL to left PTL was stronger in controls (mean $=0.58, \mathrm{SD}=0.32$ ) than in patients $\left(\right.$ mean $\left.=0.24, \mathrm{SD}=0.17 ; F_{(1,18)}=8.88, p=0.008\right)$. In the right hemisphere, contralateral to the lesion, the backward connection from AmTL to PTL was greater for patients (mean $=0.54, \mathrm{SD}=0.21)$ than for controls (mean $=0.29$, $\left.\mathrm{SD}=0.21 ; F_{(1,18)}=7.12, p=0.016\right)$.

\section{Relationship between connectivity and task performance}

We assessed the behavioral significance of effective connectivity measures by correlating the scores derived from the naming task (i.e., accuracy and types of errors) with the effective connectivity parameters. We also estimated the relationship between connectivity measures and performance on the semantic memory tests. In the group of controls, the forward connectivity from left AmTL to left inferior frontal gyrus was positively correlated with performance in the Cambridge 64-item naming task $(r=0.65$, $p=0.044)$, and showed a trend for negative correlation with SemErr (i.e., proportion of semantic errors; $r=-0.61, p=$ $0.063)$. We also observed that category fluency for birds and breeds of dogs was positively correlated with backward connectivity from left AmTL to left PTL across participants $(r=0.52$, $p=0.020 ; r=0.57, p=0.009$, respectively).

\section{Discussion}

We used DCM for event-related responses to investigate the consequences that small lesions centered on the left anteroventral temporal lobe (AvTL) have on the functional interactions within the neural networks required for naming a pictured object. To our knowledge, this is the first work studying effective connectivity in relation to the impact of ATL damage on semantic processing. Using this approach we could examine the causal influences in the network and ask whether and how connections involving the ATL were affected. Bayesian model comparison was used to compare different models (Fig. 2d) and to find the model that best explained the data (Penny et al., 2004). Model evidence was 
Controls

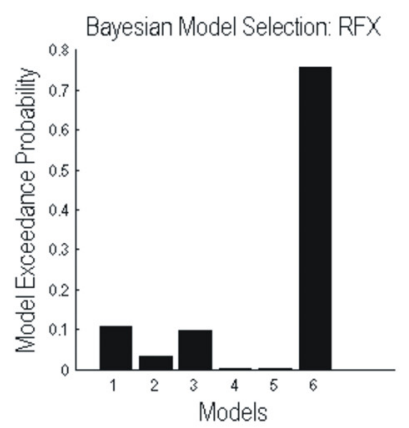

b
Patients

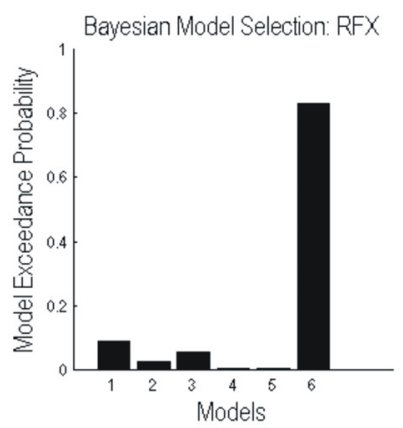

Controls \& Patients
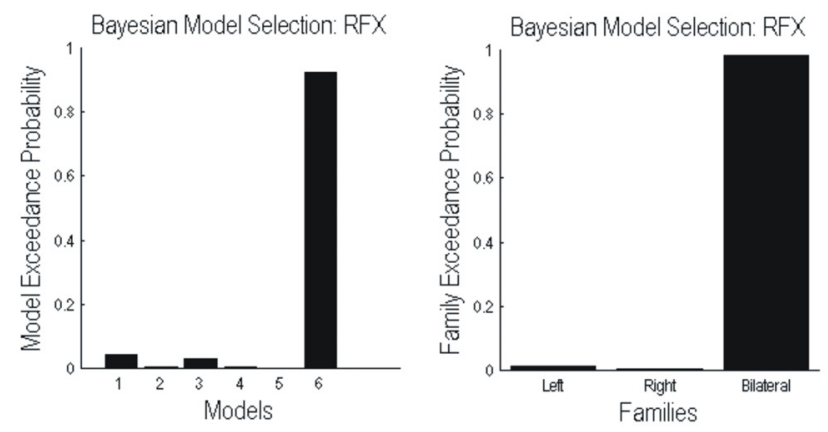

C Differences in connectivity parameters
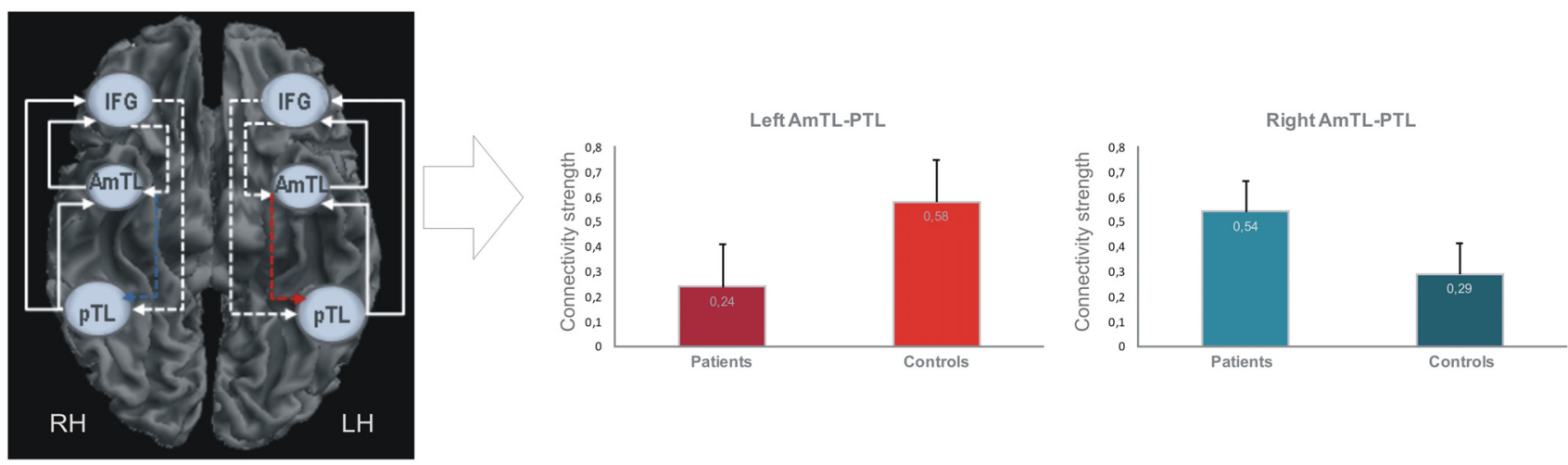

Figure 3. a1, Bayesian model selection among the six models; and between families of models ( $(\boldsymbol{a} 2)$. Random fixed effects (RFX) showed model expected probability and model exceedance probability. $\boldsymbol{b}$, results indicate that Model 6 had the greatest evidence (exceedance probability $=0.931$ ); and its subject-specific parameters (restricted to posterior probabilities of $90 \%$ or more) were selected to test for group differences (c). Red indicates differences in left hemisphere and blue indicates differences in right hemisphere.

tested separately for both groups, and also across participants, revealing that the best network architecture was characterized by bilateral sources with forward and backward connections (Fig. $3 a, b)$. Comparison of families regarding the laterality of the network showed that bilateral models were more likely. The identification of bilateral models as better explaining the data supports an influential model postulating that conceptual representations rely on a bilateral anterior temporal network (Lambon Ralph et al., 2001; Patterson et al., 2007). It is also worth noting the presence of feedback functional pathways in the winning model, as this type of connections, which provides top-down influences on antecedent cortical areas, is considered essential in recent models of visual object processing (Gilbert and Li, 2013; Kravitz et al., 2013).

Comparison of specific network parameters between groups revealed selective network adjustments in patients, characterized by a decreased backwards connectivity from AmTL to PTL in the ipsilesional hemisphere, and an enhancement in the contralesional hemisphere; right AmTL to right PTL. Additionally, differences in neural activation between groups were located in the left posterior inferior temporo-occipital cortex between 200 and 300 ms (Clarke et al., 2013). A previous PET study comparing patients with semantic dementia and healthy controls during a semantic decision task also found differences in a very similar location (Mummery et al., 1999), which were interpreted as a decrease in normal function due to reduced input from ATL. Functional deafferentiation between ATL and PTL has been also invoked to explain naming difficulties in patients with damage in left temporal lobe structures (Trebuchon-Da Fonseca et al., 2009;
Schwartz et al., 2011). Critically, recent MEG studies (Bar et al., 2006; Clarke et al., 2011) have demonstrated that phase synchronization between anterior regions (i.e., orbitofrontal cortex or ATL) and posterior sites in the temporal lobe was associated with semantic processing of visual objects, and modulated by increasing semantic integration demands (Clarke et al., 2011; Chan et al., 2011). Although such analysis lacks directionality, anterior areas were thought to provide feedback to posterior object representation sites. Differently from these studies, using DCM, we were able to evaluate the directionality of the causal interactions among brain regions and their associated connectivity strengths (Bianchi et al., 2013). We found that small lesions centered on left ATL weakened its backwards connections with left PTL. The ATL is considered a convergence region (Damasio, 1989), functioning as an intermediating representational layer, in computational terms (Lambon Ralph et al., 2010b ), "that serves to map between the modality-specific regions that encode particular perceptual attributes, words, and actions" (Rogers et al., 2007). Unlike traditional views of object and meaning processing, recent models propose that feedforward connections have a countercurrent stream of processing, by means of which high-order representations dynamically influence neurons at the antecedent stages in the cortical hierarchy (Hochstein and Ahissar, 2002; Ueno et al., 2011; Gilbert and Li, 2013; Kravitz et al., 2013). Disruption of fine-grained differentiation of words has been related to the degree of damage to a subset of ATL structures (Hurley et al., 2012); and disambiguation of perceptually and semantically confusable objects has been linked with perirhinal cortex (Kivisaari et al., 2012). Furthermore, recent evidence suggests that recurrent pro- 
jections from AmTL to posterior fusiform regions are necessary for object recognition, especially when semantic integration demands are increased (Tyler et al., 2004; Clarke et al., 2011). Using a neuroanatomically constrained computational model, Ueno et al. (2011) demonstrated an impaired naming, especially for lowfrequency words, following damage to ATL components. Interestingly, our patients showed a trend to make more errors when naming low-frequency objects (Lambon Ralph et al., 1998; Jefferies et al., 2009; Hoffman et al., 2012), and significantly more errors when naming low-frequency/artificial items (Proverbio et al., 2007). Thus, alteration of these feedback connections appears to have a negative impact on semantic processing, which was more evident for low-frequency items. We also found that nonnaming responses (i.e., omissions) were the type of error that patients made significantly more than controls. This type of error is the most pervasive impairment in semantic dementia (Woollams et al., 2008; Hurley et al., 2012), increasing with the severity of the disease (Rogers et al., 2004), and has been associated with ATL damage in other conditions (Trebuchon-Da Fonseca et al., 2009; Lambon Ralph et al., 2010a; Walker et al., 2011), but also with PTL lesions (Antonucci et al., 2008). Thus, disruption of the integrated activity between AmTL and PTL could constitute an important clue to understand the mechanisms underlying this naming impairment. The functional relevance of left AmTL-PTL interaction was emphasized by its relationship with participants' category fluency performance. Interestingly, the left inferior longitudinal fasciculus has been correlated with semantic fluency (Agosta et al., 2010; de Zubicaray et al., 2011).

Concerning findings in the contralesional hemisphere, a previous study showed a reduction in structural connections in the pathological left hemisphere and greater contralesional structural connections in patients with TLE (Powell et al., 2007). These findings suggest a greater recruitment of network resources in the unaffected hemisphere (Koylu et al., 2006; Lambon Ralph et al., 2012) that are homotopic to those in the ipsilesional hemisphere. Nonetheless, this contralesional enhancement could not be considered functional, as we did not find any significant correlation with performance (Maccotta et al., 2007). Thus, it appears that it is the functional integrity of AmTL-PTL connection in the ipsilesional hemisphere what determines the efficiency of the semantic processing (Powell et al., 2007).

We observed that left AmTL-IFC feedforward connectivity was positively related with accuracy in the Cambridge naming task, and negatively with SemErr in controls. These findings are consistent with previous studies suggesting that object recognition depends on frontotemporal interactions (Bar et al., 2006; Agosta et al., 2010; Wei et al., 2012; Bianchi et al., 2013), and specifically with the role of inferior frontal regions with semantic selection/retrieval (Binney et al., 2010, 2012). It could also reflect the semantic input to speech production/naming (Lambon Ralph et al., 2001; Ueno et al., 2011).

The pattern of naming deficits could suggest a postsemantic difficulty affecting the access to phonological representations of object's name (Hurley et al., 2012). However, we found that patients' performance was also impaired in tests of category fluency and in a visual semantic association task. This pattern of verbal and nonverbal semantic deficits constitutes an empirical support for the distributed-plus-hub hypothesis, according to which damage to the ATL would produce a semantic impairment that is modality-independent (Patterson et al., 2007). This impairment is subtle in the case of unilateral damage (Antonucci et al., 2008; Lambon Ralph et al., 2012; Schapiro et al., 2013), probably due to redundancy of the system (Lambon Ralph et al., 2010a). Using
rTMS, Pobric et al., (2007, 2010) demonstrated a categorygeneral impairment following ATL stimulation, although more posteriorly located than lesions in our patients, which was observed in the slowing down of semantic processing across all types of concepts, and when more sensitive semantic tasks were used (Lambon Ralph et al., 2012). Our results are also consistent with those from a previous study showing that lateral lesions of the left temporal lobe in patients with temporal lobe epilepsy were associated with mild naming deficits presurgically (Giovagnoli et al., 2005).

In summary, current findings have contributed to characterize the consequences of small lesions in the left AvTL on semantic memory processes and on the functional networks that constitute their neural basis (Dick and Tremblay, 2012). Behaviorally, we have shown that verbal and visual semantic processing was altered in our group of patients before surgery (Lambon Ralph et al., 2012). Using DCM for evoked responses, we observed that picture naming was associated with a frontotemporal network, which was characterized by bilateral sources connected by feedforward and feedback connections. Critically, left ATL damage induced a reconfiguration of the connectivity dynamics within this network. Specifically, patients exhibited a decreased backwards connectivity from AmTL to PTL in the ipsilesional hemisphere, which was accompanied by an increase of this interactivity in the contralesional hemisphere. Finally, interactions in the left hemisphere encompassing prefrontal and temporal regions showed positive relations with semantic processing (i.e., naming and fluency) and negative relations with semantic error production. Considered together, current results reinforce the relevance of ATL in semantic memory, as well as its amodal organization, and highlight the role of the AmTL-PTL feedback connection in enabling the integration of the semantic information.

\section{References}

Agosta F, Henry RG, Migliaccio R, Neuhaus J, Miller BL, Dronkers NF, Brambati SM, Filippi M, Ogar JM, Wilson SM, Gorno-Tempini ML (2010) Language networks in semantic dementia. Brain 133:286-299. CrossRef Medline

Antonucci SM, Beeson PM, Labiner DM, Rapcsak SZ (2008) Lexical retrieval and semantic knowledge in patients with left inferior temporal lobe lesions. Aphasiology 22:281-304. CrossRef Medline

Bar M, Kassam KS, Ghuman AS, Boshyan J, Schmidt AM, Dale AM, Hämäläinen MS, Marinkovic K, Schacter DL, Rosen BR, Halgren E (2006) Topdown facilitation of visual recognition. Proc Natl Acad Sci U S A 103: 449-454. CrossRef Medline

Barense MD, Rogers TT, Bussey TJ, Saksida LM, Graham KS (2010) Influence of conceptual knowledge on visual object discrimination: insights from semantic dementia and MTL amnesia. Cereb Cortex 20:2568-2582. CrossRef Medline

Bianchi AM, Marchetta E, Tana MG, Tettamanti M, Rizzo G (2013) Frequency-based approach to the study of semantic brain networks connectivity. J Neurosci Methods 212:181-189. CrossRef Medline

Binney RJ, Embleton KV, Jefferies E, Parker GJ, Ralph MA (2010) The ventral and inferolateral aspects of the anterior temporal lobe are crucial in semantic memory: evidence from a novel direct comparison of distortion-corrected fMRI, rTMS, and semantic dementia. Cereb Cortex 20:2728-2738. CrossRef Medline

Binney RJ, Parker GJ, Lambon Ralph MA (2012) Covergent connectivity and graded specialization in the rostral human temporal lobe as revealed by diffusion-weighted imaging probabilistic tractography. J Cogn Neurosci 24:1998-2014. CrossRef Medline

Bozeat S, Lambon Ralph MA, Patterson K, Garrard P, Hodges JR (2000) Non-verbal semantic impairment in semantic dementia. Neuropsychologia 38:1207-1215. CrossRef Medline

Caramazza A, Mahon BZ (2003) The organization of conceptual knowl- 
edge: the evidence from category-specific semantic deficits. Trends Cogn Sci 7:354-361. CrossRef Medline

Chan AM, Baker JM, Eskandar E, Schomer D, Ulbert I, Marinkovic K, Cash SS, Halgren E (2011) First-pass selectivity for semantic categories in human anteroventral temporal lobe. J Neurosci 31:18119-18129. CrossRef Medline

Clarke A, Taylor KI, Tyler LK (2011) The evolution of meaning: spatiotemporal dynamics of visual object recognition. J Cogn Neurosci 23: 1887-1899. CrossRef Medline

Clarke A, Taylor KI, Devereux B, Randall B, Tyler LK (2013) From perception to conception: how meaningful objects are processed over time. Cereb Cortex 23:187-197. CrossRef Medline

Damasio AR (1989) The brain binds entitites and events by multiregional activation from convergence zones. Neural Comput 1:123-132. CrossRef

David O, Kiebel SJ, Harrison LM, Mattout J, Kilner JM, Friston KJ (2006) Dynamic causal modeling of evoked responses in EEG and MEG. Neuroimage 30:1255-1272. CrossRef Medline

de Zubicaray GI, Rose SE, McMahon KL (2011) The structure and connectivity of semantic memory in the healthy older adult brain. Neuroimage 54:1488-1494. CrossRef Medline

Dick AS, Tremblay P (2012) Beyond the arcuate fasciculus: consensus and controversy in the connectional anatomy of language. Brain 135: 3529-3550. CrossRef Medline

Felleman DJ, Van Essen DC (1991) Distributed hierarchical processing in the primate cerebral cortex. Cereb Cortex 1:1-47. CrossRef Medline

Frankó E, Insausti AM, Artacho-Perula E, Insausti R, Chavoix C (2013) Identification of the human medial temporal lobe regions on magnetic resonance images. Hum Brain Mapp, in press. CrossRef Medline

Friston K, Harrison L, Daunizeau J, Kiebel S, Phillips C, Trujillo-Barreto N, Henson R, Flandin G, Mattout J (2008) Multiple sparse priors for the M/EEG inverse problem. Neuroimage 39:1104-1120. CrossRef Medline

Friston K, Moran R, Seth AK (2013) Analysing connectivity with Granger causality and dynamic causal modelling. Curr Opin Neurobiol 23:172178. CrossRef Medline

Gilbert CD, Li W (2013) Top-down influences on visual processing. Nat Rev Neurosci 14:350-363. CrossRef Medline

Giovagnoli AR, Erbetta A, Villani F, Avanzini G (2005) Semantic memory in partial epilepsy: verbal and non-verbal deficits and neuroanatomical relationships. Neuropsychologia 43:1482-1492. CrossRef Medline

Heim S, Eickhoff SB, Ischebeck AK, Friederici AD, Stephan KE, Amunts K (2009) Effective connectivity of the left BA 44, BA 45, and inferior temporal gyrus during lexical and phonological decisions identified with DCM. Hum Brain Mapp 30:392-402. CrossRef Medline

Hillis AE (2007) Aphasia: progress in the last quarter of a century. Neurology 69:200-213. CrossRef Medline

Hitomi T, Koubeissi MZ, Kaffashi F, Turnbull J, Lüders HO (2013) Visual processing in the inferior temporal cortex: an intracranial event related potential study. Clin Neurophysiol 124:164-170. CrossRef Medline

Hochstein S, Ahissar M (2002) View from the top: hierarchies and reverse hierarchies in the visual system. Neuron 36:791-804. CrossRef Medline

Hoffman P, Jones RW, Lambon Ralph MA (2012) The degraded concept representation system in semantic dementia: damage to pan-modal hub, then visual spoke. Brain 135:3770-3780. CrossRef Medline

Hurley RS, Paller KA, Rogalski EJ, Mesulam MM (2012) Neural mechanisms of object naming and word comprehension in primary progressive aphasia. J Neurosci 32:4848-4855. CrossRef Medline

Insausti R, Juottonen K, Soininen H, Insausti AM, Partanen K, Vainio P, Laakso MP, Pitkänen A (1998) MR volumetric analysis of the human entorhinal, perirhinal, and temporopolar cortices. AJNR Am J Neuroradiol 19:659-671. Medline

Ives-Deliperi VL, Butler JT (2012) Naming outcomes of anterior temporal lobectomy in epilepsy patients: a systematic review of the literature. Epilepsy Behav 24:194-198. CrossRef Medline

Jefferies E, Patterson K, Jones RW, Lambon Ralph MA (2009) Comprehension of concrete and abstract words in semantic dementia. Neuropsychology 23:492-499. CrossRef Medline

Kilner JM, Friston KJ (2010) Topological inference for EEG and MEG. Ann Appl Stat 14:1272-1290. CrossRef

Kivisaari SL, Tyler LK, Monsch AU, Taylor KI (2012) Medial perirhinal cortex disambiguates confusable objects. Brain 135:3757-3769. CrossRef Medline

Koubeissi MZ, Lesser RP, Sinai A, Gaillard WD, Franaszczuk PJ, Crone NE
(2012) Connectivity between perisylvian and bilateral basal temporal cortices. Cereb Cortex 22:918-925. CrossRef Medline

Köylü B, Trinka E, Ischebeck A, Visani P, Trieb T, Kremser C, Bartha L, Schocke M, Benke T (2006) Neural correlates of verbal semantic memory in patients with temporal lobe epilepsy. Epilepsy Res 72:178-191. CrossRef Medline

Kravitz DJ, Saleem KS, Baker CI, Ungerleider LG, Mishkin M (2013) The ventral visual pathway: an expanded neural framework for the processing of object quality. Trends Cogn Sci 17:26-49. CrossRef Medline

Lambon Ralph MA, Graham KS, Ellis AW, Hodges JR (1998) Naming in semantic dementia: what matters? Neuropsychologia 36:775-784. CrossRef Medline

Lambon Ralph MA, McClelland JL, Patterson K, Galton CJ, Hodges JR (2001) No right to speak? The relationship between object naming and semantic impairment: neuropsychological evidence and a computational model. J Cogn Neurosci 13:341-356. CrossRef Medline

Lambon Ralph MA, Cipolotti L, Manes F, Patterson K (2010a) Taking both sides: do unilateral anterior temporal lobe lesions disrupt semantic memory? Brain 133:3243-3255. CrossRef Medline

Lambon Ralph MA, Sage K, Jones RW, Mayberry EJ (2010b) Coherent concepts are computed in the anterior temporal lobes. Proc Natl Acad Sci U S A 107:2717-2722. CrossRef Medline

Lambon Ralph MA, Ehsan S, Baker GA, Rogers TT (2012) Semantic memory is impaired in patients with unilateral anterior temporal lobe resection for temporal lobe epilepsy. Brain 135:242-258. CrossRef Medline

Maccotta L, Buckner RL, Gilliam FG, Ojemann JG (2007) Changing frontal contributions to memory before and after medial temporal lobectomy. Cereb Cortex 17:443-456. CrossRef Medline

Mattout J, Henson RN, Friston KJ (2007) Canonical source reconstruction for MEG. Comput Intell Neurosci 67613. CrossRef Medline

Meehan TP, Bressler SL (2012) Neurocognitive networks: findings, models, and theory. Neurosci Biobehav Rev 36:2232-2247. CrossRef Medline

Mikuni N, Miyamoto S, Ikeda A, Satow T, Taki J, Takahashi J, Ohigashi Y, Hashimoto N (2006) Subtemporal hippocampectomy preserving the basal temporal language area for intractable mesial temporal lobe epilepsy: preliminary results. Epilepsia 47:1347-1353. CrossRef Medline

Mion M, Patterson K, Acosta-Cabronero J, Pengas G, Izquierdo-Garcia D, Hong YT, Fryer TD, Williams GB, Hodges JR, Nestor PJ (2010) What the left and right anterior fusiform gyri tell us about semantic memory. Brain 133:3256-3268. CrossRef Medline

Moran RJ, Campo P, Symmonds M, Stephan KE, Dolan RJ, Friston KJ (2013) Free energy, precision and learning: the role of cholinergic neuromodulation. J Neurosci 33:8227-8236. CrossRef Medline

Müller MM, Andersen SK, Keil A (2008) Time course of competition for visual processing resources between emotional pictures and foreground task. Cereb Cortex 18:1892-1899. CrossRef Medline

Mummery CJ, Patterson K, Wise RJ, Vandenberghe R, Price CJ, Hodges JR (1999) Disrupted temporal lobe connections in semantic dementia. Brain 122:61-73. CrossRef Medline

Noppeney U, Patterson K, Tyler LK, Moss H, Stamatakis EA, Bright P, Mummery C, Price CJ (2007) Temporal lobe lesions and semantic impairment: a comparison of herpes simplex virus encephalitis and semantic dementia. Brain 130:1138-1147. CrossRef Medline

Patterson K, Nestor PJ, Rogers TT (2007) Where do you know what you know? The representation of semantic knowledge in the human brain. Nat Rev Neurosci 8:976-987. CrossRef Medline

Penny WD, Stephan KE, Mechelli A, Friston KJ (2004) Comparing dynamic causal models. Neuroimage 22:1157-1172. CrossRef Medline

Penny WD, Stephan KE, Daunizeau J, Rosa MJ, Friston KJ, Schofield TM, Leff AP (2010) Comparing families of dynamic causal models. PLoS Comput Biol 6:e1000709. CrossRef Medline

Phan TG, Fong AC, Donnan G, Reutens DC (2007) Digital map of posterior cerebral artery infarcts associated with posterior cerebral artery trunk and branch occlusion. Stroke 38:1805-1811. CrossRef Medline

Pobric G, Jefferies E, Ralph MA (2007) Anterior temporal lobes mediate semantic representation: mimicking semantic dementia by using rTMS in normal participants. Proc Natl Acad Sci US A 104:20137-20141. CrossRef Medline

Pobric G, Jefferies E, Lambon Ralph MA (2010) Category-specific versus category-general semantic impairment induced by transcranial magnetic stimulation. Curr Biol 20:964-968. CrossRef Medline

Powell HW, Parker GJ, Alexander DC, Symms MR, Boulby PA, Wheeler- 
Kingshott CA, Barker GJ, Koepp MJ, Duncan JS (2007) Abnormalities of language networks in temporal lobe epilepsy. Neuroimage 36:209-221. CrossRef Medline

Proverbio AM, Del Zotto M, Zani A (2007) The emergence of semantic categorization in early visual processing: ERP indices of animal vs artifact recognition. BMC Neurosci 8:24. CrossRef Medline

Roach A, Schwartz MF, Martin N, Grewal RS, Brecher A (1996) The Philadelphia naming test: scoring and rationale. Clin Aphasiol 24:121-133.

Rogers TT, Lambon Ralph MA, Garrard P, Bozeat S, McClelland JL, Hodges JR, Patterson K (2004) Structure and deterioration of semantic memory: a neuropsychological and computational investigation. Psychol Rev 111:205-235. CrossRef Medline

Rogers TT, Patterson K, Graham K (2007) Colour knowledge in semantic dementia: it is not all black and white. Neuropsychologia 45:3285-3298. CrossRef Medline

Sanfeliú MC, Fernández A (1996) A set of 254 Snodgrass-Vanderwart pictures standardized for Spanish: norms for name agreement, image agreement, familiarity and visual complexity. Behav Res Methods Instr Comput 28:537-555. CrossRef

Schapiro AC, McClelland JL, Welbourne SR, Rogers TT, Lambon Ralph MA (2013) Why bilateral damage is worse than unilateral damage to the brain. J Cogn Neurosci, in press. CrossRef Medline

Schwartz MF, Kimberg DY, Walker GM, Faseyitan O, Brecher A, Dell GS, Coslett HB (2009) Anterior temporal involvement in semantic word retrieval: voxel-based lesion-symptom mapping evidence from aphasia. Brain 132:3411-3427. CrossRef Medline

Schwartz MF, Kimberg DY, Walker GM, Brecher A, Faseyitan OK, Dell GS, Mirman D, Coslett HB (2011) Neuroanatomical dissociation for taxonomic and thematic knowledge in the human brain. Proc Natl Acad Sci U S A 108:8520-8524. CrossRef Medline

Sebastián N, Martí MA, Carreiras MF, Cuetos F, eds (2000) LEXESP. Léxico informatizado del español. Barcelona: Ediciones de la Universitat de Barcelona.

Seghier ML, Zeidman P, Neufeld NH, Leff AP, Price CJ (2010) Identifying abnormal connectivity in patients using dynamic causal modeling of FMRI responses. Front Syst Neurosci 4:142. CrossRef Medline

Stephan KE, Friston KJ (2007) Models of effective connectivity in neural systems. In: Handbook of brain connectivity: understanding complex systems (Jirsa VK, McIntosh AR, eds), pp 303-326. Berlin: Springer.

Taulu S, Hari R (2009) Removal of magnetoencephalographic artifacts with temporal signal-space separation: demonstration with single-trial auditory-evoked responses. Hum Brain Mapp 30:1524-1534. CrossRef Medline

Trebuchon-Da Fonseca A, Guedj E, Alario FX, Laguitton V, Mundler O, Chauvel P, Liegeois-Chauvel C (2009) Brain regions underlying word finding difficulties in temporal lobe epilepsy. Brain 132:2772-2784. CrossRef Medline

Tsapkini K, Frangakis CE, Hillis AE (2011) The function of the left anterior temporal pole: evidence from acute stroke and infarct volume. Brain 134: 3094-3105. CrossRef Medline

Tyler LK, Stamatakis EA, Bright P, Acres K, Abdallah S, Rodd JM, Moss HE (2004) Processing objects at different levels of specificity. J Cogn Neurosci 16:351-362. CrossRef Medline

Ueno T, Saito S, Rogers TT, Lambon Ralph MA (2011) Lichtheim 2: synthesizing aphasia and the neural basis of language in a neurocomputational model of the dual dorsal-ventral language pathways. Neuron 72:385-396. CrossRef Medline

Visser M, Lambon Ralph MA (2011) Differential contributions of bilateral ventral anterior temporal lobe and left anterior superior temporal gyrus to semantic processes. J Cogn Neurosci 23:3121-3131. CrossRef Medline

Walker GM, Schwartz MF, Kimberg DY, Faseyitan O, Brecher A, Dell GS, Coslett HB (2011) Support for anterior temporal involvement in semantic error production in aphasia: new evidence from VLSM. Brain Lang 117:110-122. CrossRef Medline

Warren JE, Crinion JT, Lambon Ralph MA, Wise RJ (2009) Anterior temporal lobe connectivity correlates with functional outcome after aphasic stroke. Brain 132:3428-3442. CrossRef Medline

Wei T, Liang X, He Y, Zang Y, Han Z, Caramazza A, Bi Y (2012) Predicting conceptual processing capacity from spontaneous neuronal activity of the left middle temporal gyrus. J Neurosci 32:481-489. CrossRef Medline

Woollams AM, Cooper-Pye E, Hodges JR, Patterson K (2008) Anomia: a doubly typical signature of semantic dementia. Neuropsychologia 46 : 2503-2514. CrossRef Medline

Wright P, Stamatakis EA, Tyler LK (2012) Differentiating hemispheric contributions to syntax and semantics in patients with left-hemisphere lesions. J Neurosci 32:8149-8157. CrossRef Medline

Yvert G, Perrone-Bertolotti M, Baciu M, David O (2012) Dynamic causal modeling of spatiotemporal integration of phonological and semantic processes: an electroencephalographic study. J Neurosci 32:4297-4306. CrossRef Medline 